\title{
Residual tau-fluvalinate in honey bee colonies is coupled with evidence for selection for Varroa destructor resistance to pyre- throids
}

\author{
María Benito-Murcia ${ }^{1}$, Carolina Bartolomé ${ }^{2,3}$, Xulio Maside ${ }^{2,3}$, José Bernal ${ }^{4}$, José Luis Bernal ${ }^{4}$, María Jesús del \\ Nozal $^{4}$, Aránzazu Meana ${ }^{5}$, Cristina Botías ${ }^{1}$, Raquel Martín-Hernández ${ }^{1,6}$ and Mariano Higes 1,*
}

${ }^{1}$ Instituto Regional de Investigación y Desarrollo Agroalimentario y Forestal (IRIAF), Laboratorio de Patología Apícola, Centro de Investigación Apícola y Agroambiental (CIAPA), Junta de Comunidades de Castilla-La Mancha, Marchamalo, 19180, Spain; mbmurcia@jccm.es; cbotias@jccm.es; rmhernandez@jccm.es; mhiges@jccm.es

${ }_{2}^{2}$ Grupo de Medicina Xenómica, CIMUS, Universidade de Santiago de Compostela, Santiago de Compostela, Galicia, 15782, Spain. carolina.bartolome@usc.es; xulio.maside@usc.es

${ }^{3}$ Instituto de Investigación Sanitaria de Santiago (IDIS), Santiago de Compostela, Galicia, 15706, Spain. carolina.bartolome@usc.es; xulio.maside@usc.es

${ }^{4}$ I. U. CINQUIMA, Analytical Chemistry Group, Faculty of Sciences, University of Valladolid, Valladolid, Spain. Joseluis.bernal@uva.es; mjdnozal@uva.es

${ }^{5}$ Department of Animal Health, Faculty of Veterinary Medicine, Complutense University of Madrid, 28040. ameana@ucm.es

${ }^{6}$ Instituto de Recursos Humanos para la Ciencia y la Tecnología (INCRECYT-FEDER), Fundación Parque Científico y Tecnológico de Castilla - La Mancha, Spain

* Correspondence: mhiges@jccm.es

Simple Summary: Varroa destructor is one of the most prevalent honey bees (Apis mellifera) pathogens worldwide. Nowadays, the main method to control this parasite involves the application of different acaricidal treatments, among which the pyrethroid tau-fluvalinate is one of the most widely used. However, the intensive and repetitive application of these chemicals generates a selective pressure that, when maintained over time, contributes to the emergence of resistant mites in the honey bee colonies. Here we analysed the presence of residual tau-fluvalinate and the patterns of genetic resistance to this acaricide in Varroa mites collected from tau-fluvalinate untreated honey bee colonies. Our results show the widespread and persistent pyrethroid contamination of beeswax and beebread in the hives, along with an excess of pyrethroid resistant genotypes and an overall increase in the frequency of the pyrethroid resistant allele in the mite population over time. Persistent contamination of the hives likely compromises the efficacy of tau-fluvalinate treatments and, therefore, may have serious long-term consequences for the control of varroosis.

\begin{abstract}
Varroa destructor is considered one of the most devastating parasites of the honey bee, Apis mellifera, and a major problem for the beekeeping industry. Currently, the main method to control Varroa mites is the application of drugs that contain different acaricides as active ingredients. The pyrethroid tau-fluvalinate is one of the acaricides most widely used in beekeeping due to its efficacy and low toxicity to bees. However, the intensive and repetitive application of this compound produces a selective pressure that, when maintained over time, contributes to the emergence of resistant mites in the honey bee colonies, compromising the acaricidal treatments efficacy. Here we studied the presence of tau-fluvalinate residues in hives and the evolution of genetic resistance to this acaricide in Varroa mites from honeybee colonies that received no pyrethroid treatment in the previous four years. Our data revealed the widespread and persistent tau-fluvalinate contamination of beeswax and beebread in hives, an overall increase of the pyrethroid resistance allele frequency and a generalized excess of resistant mites relative to Hardy-Weinberg equilibrium expectations. These results suggest that tau-fluvalinate contamination of the hives may seriously compromise the efficacy of pyrethroid-based mite control methods.
\end{abstract}


Keywords: Varroa destructor, mite, resistant populations, acaricide residues, tau-fluvalinate, varroosis.

\section{Introduction}

The ectoparasitic honey bee mite Varroa destructor (Acari: Varroidae, Anderson \& Trueman, 2000) is widespread in Apis mellifera (Hymenoptera: Apidae, Linnaeus, 1758) colonies worldwide after it shifted from its original host, the Eastern honey bee Apis cerana (Hymenoptera: Apidae, Fabricius, 1793) [1]. It is considered a major problem for beekeeping [2], with the potential to affect individual bees and whole honey bee colonies, and if not treated adequately it can ultimately lead to colony loss within 2-3 years [1]. Indeed, several factors contribute to the dramatic effect of Varroa infection on honey bee populations, including a direct effect on the feeding of immature and adult bees, as well as serving as a vector for several debilitating viruses $[1,3-6]$.

Currently, the main method to control Varroa mites is the application of veterinary drugs based on different compounds with acaricide activity. However, after several decades using these compounds a loss of their efficacy is a reality in many countries, as intensive and repetitive use may exert a selective pressure that favours the emergence of resistant mite populations [7-13]. Tau-fluvalinate is one of the most widely used acaricides in beekeeping due to its efficacy and low bee toxicity [14]. Thus, intensive and repetitive application of this drug is associated with the detection of resistant mite populations, first in Italy in the 1990s [15] and subsequently elsewhere [16].

Tau-fluvalinate is a pyrethroid that targets voltage-gated sodium channels (VGSCs), disrupting their activity in neural signalling and producing paralysis in affected arthropods. Pyrethroid resistance, especially extreme resistance known as knockdown resistance ( $k d r)$, has been attributed to mutations of key residues in VGSCs [17]. Indeed, several point mutations in the III and IV domains of VGSC genes have been identified in resistant Varroa mites [18]. More recently, several amino acid substitutions were also described in domain II at position 925 (numbered according to Musca domestica Linnaeus (Diptera: Muscidae)), lying in segment 5 of the VGSC helix that is the region in which a hydrophobic cavity is formed for pyrethroid binding [19]. As such, three different resistant alleles have been described at this position, replacing wild-type leucine with valine (L925V), isoleucine (L925I) or methionine (L925M) [10, 20-25]. Accordingly, the $\mathrm{L} 925 \mathrm{~V}$ in $V$. destructor appears to be a key change in $k d r$ and the presence of populations carrying these mutations may be favoured when acaricide treatments containing pyrethroids are maintained over time.

Due to the high levels of miticides and agrochemicals found in wax and pollen around the world and given that these are mainly pyrethroids [26-33], we set out to investigate the possible relationship between such residues in wax and beebread, and their interaction with Varroa mite populations. In this way, our aim was to better understand whether the persistence of such residues might be responsible for favouring the emergence of Varroa resistant mites, since beekeepers frequently report problems in controlling varroosis with these acaricides after years of not using them.

\section{Materials and Methods}

\subsection{Honey bee colonies selection and location}


This study was carried out from October 2018 to October 2019 on 10 honey bee colonies that had not received any acaricide treatment with veterinary drugs containing pyrethroids as active ingredient (Apistán ${ }^{\circ}$, active substance: tau-fluvalinate. Bayvarol $\AA$, active substance: flumethrin) in the previous 48 months (since October 2014) and that displayed natural parasitization by $V$. destructor. The bee colonies were located in an experimental apiary at CIAPA (Marchamalo, central Spain, LT: 40.687756-LG: -3.218516), separated more than $5 \mathrm{~km}$ from other apiaries not belonging to our centre that could alter the results of the study.

\subsection{Wax and beebread samples}

\subsubsection{Sample collection}

Wax and beebread samples ( $n=26$ of each type) were collected in different time points (winter 2018, spring 2019 and autumn 2019, Figure 1) in order to evaluate the presence of tau-fluvalinate residues in the experimental colonies. For wax sampling, brood chamber combs (empty and with beebread) were taken from each hive and then, 4 pieces of wax $(4 \times 4 \mathrm{~cm})$ were collected from different parts of the combs. Beebread $(10 \mathrm{~g})$ was taken randomly from different cells of combs with this matrix, using sterile stainlesssteel spatulas. All the samples were kept at $-20{ }^{\circ} \mathrm{C}$.

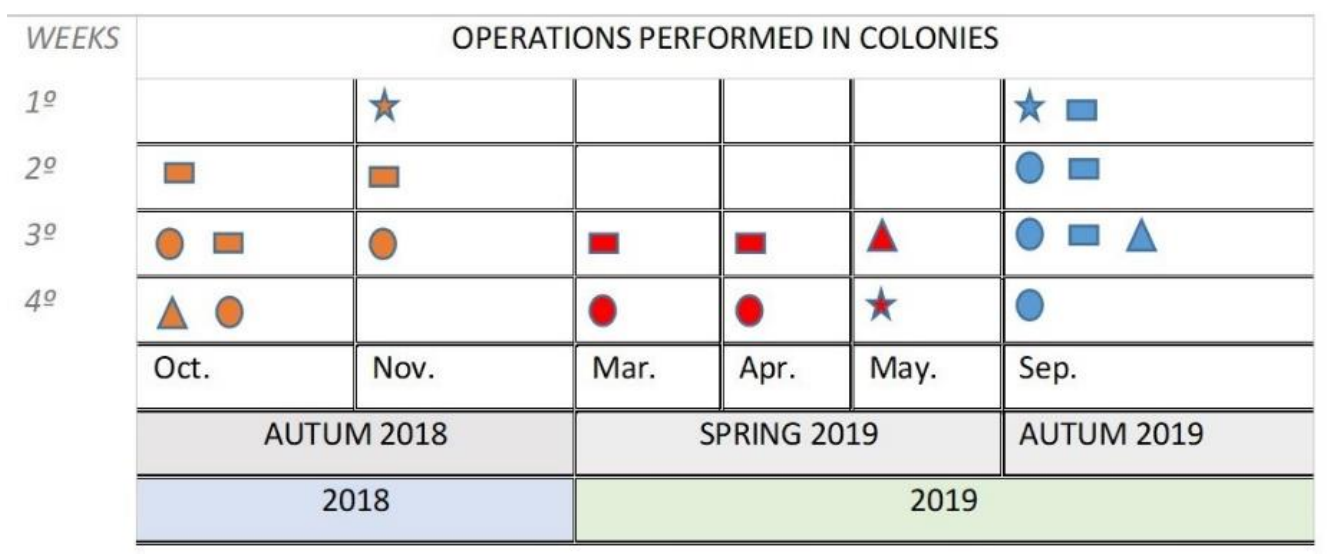

Figure 1. Chronology of the operations performed in the colonies. Rectangle: put clean sanitary bottom. Circle: remove sanitary bottom. Star: treatment against $V$. destructor with amitraz. Triangle: wax and beebread sampling. Each color refers to the different sampling periods.

\subsubsection{Chemical analysis}

The wax and beebread samples were sent on dry ice to the Analytical Chemistry Group of University of Valladolid (I.U. CINQUIMA, Spain) for analysis.

The presence of tau-fluvalinate was analysed in a GC-MS system using a method described previously [34]. Extraction was firstly carried out by a modified version of the QuEChERS method [27] [35]. Briefly, $2 \mathrm{~g}$ of wax or $0.5 \mathrm{~g}$ of pollen was added to a $50 \mathrm{~mL}$ polypropylene centrifuge tube containing $10 \mathrm{~mL}$ of acetonitrile-acetic acid $(99: 1, \mathrm{v} / \mathrm{v})$, mixed by vortexing for $15 \mathrm{sec}$ and then for $3 \mathrm{~min}$ with an Ultra Turrax homogenizer. The samples were centrifuged at 10,000 rpm for $5 \mathrm{~min}$ at $5{ }^{\circ} \mathrm{C}$, and $5 \mathrm{~mL}$ of the extract was added to a dSPE EMR-lipid cartridge (Agilent), vortexed for $30 \mathrm{sec}$ and centrifuged for 5 $\mathrm{min}$ at 7,500 rpm and $5{ }^{\circ} \mathrm{C}$. The supernatant $(5 \mathrm{~mL})$ was then pipetted into a $15 \mathrm{~mL}$ centrifuge tube containing the "Final Polish EMR-lipid" sorbent (Agilent), vortexed for 30 $\mathrm{sec}$ and then centrifuged for $5 \mathrm{~min}$ at 7,500 rpm and $5^{\circ} \mathrm{C}$. Subsequently, $2 \mathrm{~mL}$ of the supernatant was placed in a round bottom flask, evaporated to dryness in a rotary evaporator and re-dissolved in $1 \mathrm{~mL}$ of an ethyl acetate-cyclohexane mixture (20:80, v/v) in an 
ultrasound bath. The sample was then analysed on an Agilent GC with a 5975-quadruple mass detector using chlorfenvinphos-D10 as the internal standard.

\subsection{Varroa mite collection and genotyping}

\subsubsection{Mite collection}

Adult female Varroa mites were sampled at 9 time points throughout the study (see Figure 1), which includes samples taken before and after the application of mandatory acaricide treatments with Apitraz ${ }^{\circledR}$ strips (2 strips/hive, active ingredient: $500 \mathrm{mg}$ of amitraz per strip), as indicated in the Spanish legislation on the control of varroosis [36]. The mites were sampled from the bottom of the hives [37] by placing a tray at the sanitary bottom of every hive for one week. For each sampling date, 40 mites per colony were collected from these trays in the laboratory using sterile tweezers when it was possible. When there were fewer than 40 mites, all the mites available were collected from the tray. The mites collected were all then stored at $-20^{\circ} \mathrm{C}$ for later DNA extraction.

\subsubsection{DNA extraction and PCR-RLFP assay}

Individual mites were ground in separate wells in a 96-well plate (Qiagen), to which 200 $\mu \mathrm{L}$ of sterile $\mathrm{H} 2 \mathrm{O}$ miliQ and three stainless steel beads were added, shaking the plates for 1.5 minutes in a TissueLyser II machine at $30 \mathrm{~Hz}$ (Qiagen, Cat No./ID: 85300). Subsequently, $150 \mu \mathrm{l}$ of the macerate was incubated overnight at $56{ }^{\circ} \mathrm{C}$ with $20 \mu \mathrm{l}$ of Proteinase K (Qiagen, Cat No./ID: 19133) as described elsewhere [38]. Genomic DNA was extracted in a Biosprint workstation (Qiagen) using the BioSprint 96 DNA Blood Kit (Qiagen, Cat No./ID: 940057) following the BS96 DNA Tissue protocol Negative controls were included for each step of the process and finally. The plates were stored at $-20{ }^{\circ} \mathrm{C}$.

The genotype of the mites at position 925 (domain II) of the VGSC gene was determined by the PCR-RFLP protocol described previously [39]. Briefly, the PCR reaction mixtures were performed with $0.5 \mu \mathrm{M}$ of each oligonucleotide primer (Forward primer [1273IF_VD] 5'- AAGCCGCCATTGTTACCAGA-3'; Reverse primer [1973-IR_VD] 5'-CTGTTGTTACCGTGGAGCA-3'), $0.5 \mu \mathrm{l}$ of BSA + Triton X-100, and $2.5 \mu l$ genomic DNA and $12.5 \mu \mathrm{l}$ of the Fast Start PCR Master mix (Cat No. 04710452001 Roche Diagnostic) in a final volume of $25 \mu \mathrm{l}$. The cycling conditions were: $10 \mathrm{~min}$ at $95^{\circ} \mathrm{C} ; 35$ cycles of $30 \mathrm{~s}$ at 95 ${ }^{\circ} \mathrm{C}, 30 \mathrm{~s}$ at $60{ }^{\circ} \mathrm{C}, 45 \mathrm{~s}$ at $72{ }^{\circ} \mathrm{C}$; and a final extension for $7 \mathrm{~min}$ at $72{ }^{\circ} \mathrm{C}$. All reactions were carried out in a Mastercycler ep gradient $S$ (Eppendorf) and analysed in a QIAxcel Advanced System (Qiagen) using a QIAxcel DNA Screening Kit to confirm amplification (Qiagen, Cat No. 929004). Subsequently, $15 \mu$ l of each PCR products was mixed with 2.5 $\mathrm{U}$ of SacI (Thermofisher Scientific, Cat No: \#ER1131) and $3 \mu \mathrm{l}$ of $10 \times$ SacI buffer in a final volume of $20 \mu \mathrm{l}$, and the products were digested for 4 to $16 \mathrm{~h}$ at $37^{\circ} \mathrm{C}$. This digestion should generate two fragments ( $264 \mathrm{bp}$ and $436 \mathrm{bp}$ ) from the wild-type genotype and a single 700 bp 'undigested' fragment in the case of the resistant strains. Finally, the products of digestion were analysed by capillary electrophoresis and visualized with a QIAxcel Advanced System (Qiagen).

To ascertain the correct genotyping classification of mites with the PCR-RLFP method used, 75 DNA samples were genotyped by Sanger sequencing. The samples were selected according to the genotypes' relative abundances: 8 resistant homozygotes, 65 sensitive homozygotes and 2 heterozygotes. DNA extracts of the samples were subject to a previously described PCR protocol [22] that amplifies a 170bp fragment of VGSC gene encompassing 'hot spot' resistance positions - including position 925-. Subsequently PCR products were purified with QIAquick PCR Purification Kit (Qiagen, Cat No./ID: 28106) and sequenced at the Universidad de Alcalá de Henares (Madrid, Spain) on an ABI3730XL Applied Biosystems system. The sequences obtained were analysed with 
BioEdit (BioEdit sequence Aligment Editor@ version 7.2.5), which allowed us to identify the different Varroa genotypes.

\subsection{Allele frequencies}

At each sampling date the allele frequencies of the sensitive (S) and resistant (R) alleles, $p$ and $q$ respectively, in each colony were estimated from the observed PCR-RFLP genotypes:

$p=(2 \mathrm{SS}+\mathrm{SR}) / 2 \mathrm{~N}$

$q=1-p$

where SS is the number of individuals homozygous for the sensitive allele; SR, the number of heterozygous; RR, the number of homozygous for the resistance allele; and $N$ is the total number of specimens analysed.

The expected genotype frequencies assuming under Hardy-Weinberg equilibrium were estimated using the usual formulae:

$\mathrm{SS}=p^{2} N ; \mathrm{SR}=(2 p q) N ; \mathrm{RR}=q^{2} N$

The deviation of the genotype frequencies observed from those expected under equilibrium were evaluated using a Chi-squared goodness of fit test.

Given that on several occasions, particularly in spring 2019, the number of mites per colony was low, to obtain more accurate estimates of the observed genotype frequencies, data were pooled across colonies for each sampling date. Before doing so, the differences among the observed genotype frequencies across colonies of each given sampling date were evaluated by means of the Chi-squared homogeneity test. No statistically significant differences were observed in all but two sampling dates: 23 Oct 2018 and 17 Sep 2019. In these cases the differences could be attributed to comparatively higher frequencies of heterozygotes in two and one colonies, respectively. However, considering that the three colonies produced similar results to the others in the anterior and posterior sampling dates, which were performed in eight-day intervals, and that they did not modify in any meaningful manner the results described in this study, the data from these samples were not removed from the analyses.

The Bonferroni correction for multiple testing and the Yates correction for continuity were applied to the Chi-squared tests when appropriate.

\section{Results}

\subsection{Tau-fluvalinate residues in wax and beebread}

The tau-fluvalinate in the wax and beebread of the hives was detected in all the samples analysed throughout the study (Table 1). The highest concentrations of the residue were detected in the beebread, with values ranging from 1,955.2 $\pm 73.8 \mathrm{ppb}$ (mean \pm standard deviation) in autumn 2018 (range 1,863.3 to 2,129.3 ppb) to a lower level of $691.7 \pm 132.3$ ppb in spring 2019 (range 450.1-901.8 ppb), before falling to $293.9 \pm 117.5$ in autumn 2019 (range 159.6-450.4 ppb). The values of the residues detected in the wax of the brood chamber combs were constant over time, with average concentrations ranging from 67.4 $\pm 25.4 \mathrm{ppb}$ in autumn 2018 to $68.3 \pm 21.9 \mathrm{ppb}$ in spring 2019 and $66.5 \pm 20.2$ in autumn 2019 (Table 1). 
Table 1. Tau-fluvalinate concentration (in ppb) detected in wax and beebread from each honey bee colony included in the study at each sampling point. S.d.: stanadard deviation.

\begin{tabular}{ccccccc}
\hline & Autumn 18 & \multicolumn{3}{c}{ Spring 19 } & Autumn 19 \\
\hline Colony & Wax & Beebread & Wax & Beebread & Wax & Beebread \\
\hline 1 & 40.2 & 1908.0 & 90.6 & 680.1 & 90.2 & 167.1 \\
2 & 24.4 & 1863.3 & 58.4 & 713.7 & 57.5 & 172.3 \\
3 & 92.1 & 1943.6 & 103.6 & 660.6 & 95.6 & 159.6 \\
4 & 82.6 & 1960.7 & 58.0 & 704.3 & 60.4 & 450.4 \\
5 & 68.2 & 1902.9 & 69.1 & 715.2 & 64.0 & 260.9 \\
6 & 107.7 & 1940.1 & 72.4 & 723.1 & 70.1 & 340.2 \\
7 & 61.3 & 1929.6 & 23.9 & 841.6 & 22.9 & 258.1 \\
8 & 70.6 & 2129.3 & 80.3 & 450.1 & 78.7 & 249.0 \\
9 & 44.9 & 1954.7 & 54.1 & 520.4 & 60.1 & 340.3 \\
10 & 82.0 & 2020.1 & 72.5 & 901.8 & 69.6 & 541.2 \\
\hline Mean & $\mathbf{6 7 . 4}$ & $\mathbf{1 9 5 5 . 2}$ & $\mathbf{6 8 . 3}$ & $\mathbf{6 9 1 . 1}$ & $\mathbf{6 6 . 9}$ & $\mathbf{2 9 3 . 9}$ \\
\hline S.d. & $\mathbf{2 5 . 4}$ & $\mathbf{7 3 . 8}$ & $\mathbf{2 1 . 9}$ & $\mathbf{1 3 2 . 3}$ & $\mathbf{2 0 . 1}$ & $\mathbf{1 2 6 . 2}$ \\
\hline
\end{tabular}

\subsection{Pyrethroid-resistance allele frequencies}

A total of $1,516 \mathrm{~V}$. destructor female mites were sampled from 10 honey bee colonies at nine different time points in 2018 and 2019. The genotype at position 925 (domain II) of the VGSC gene was determined by means of the PCR-RFLP technique (Table 2). The genotype of 75 of these mites was double-checked by Sanger sequencing of the PCR products, with identical results.

Genotype frequencies were obtained by pooling the observed frequencies across colonies at each sampling date (Table 2). In most cases the genotype frequencies departed significantly from Hardy-Weinberg equilibrium expectations (HWE). This effect could be attributed to an overall excess of mites homozygous for the resistance alleles (RR), which were $6.3 \pm 1.89$ (mean $\pm \mathrm{SE}$ ) times more abundant than expected and a concomitant dearth of SR heterozygotes $(0.6 \pm 0.10)$. Contrastingly, no departure form HWE expectations was detected for sensitive homozygotes (SS; $1.0 \pm 0.00$ ). The two treatments with amitraz had not detectable effects on the frequencies of RR individuals, as expected considering that this miticide does not target pyrethroid receptors [51].

Table 2. Genotype frequencies observed (Obs) vs. expected (Exp) under Hardy-Weinberg equilibrium. Pooled data across colonies. SS: homozygotes for the sensitive allele, SR: heterozygotes, and RR: homozygotes for the resistance allele; Obs: observed number of mites; Exp: expected number of mites under Hardy-Weinberg equilibrium; ${ }^{*}, \mathrm{P}<0.05$; ${ }^{* *}, \mathrm{P}<0.01$; ${ }^{* * *}, \mathrm{P}<0.001$; n.s., non-significant, as estimated by means of a chi-square test of goodness of fit with a Bonferroni correction for multiple testing. 


\begin{tabular}{|c|c|c|c|c|c|}
\hline Sample date & & SS & SR & $\mathbf{R R}$ & $P$ \\
\hline \multirow[t]{2}{*}{15 Oct 2018} & Obs & 242 & 9 & 4 & \\
\hline & Exp & 238.3 & 16.4 & 0.3 & $* * *$ \\
\hline \multirow[t]{2}{*}{23 Oct 2018} & Obs & 239 & 34 & 7 & \\
\hline & Exp & 234.1 & 43.9 & 2.1 & $* *$ \\
\hline \multirow[t]{2}{*}{19 Nov 2018} & Obs & 266 & 7 & 10 & \\
\hline & $\operatorname{Exp}$ & 256.6 & 25.7 & 0.6 & $* * *$ \\
\hline \multirow[t]{2}{*}{26 Mar 2019} & Obs & 28 & 6 & 0 & \\
\hline & Exp & 28.3 & 5.5 & 0.3 & n.s. \\
\hline \multirow[t]{2}{*}{29 Apr 2019} & Obs & 47 & 2 & 3 & \\
\hline & Exp & 44.3 & 7.4 & 0.3 & $* * *$ \\
\hline \multirow[t]{2}{*}{04 Sep 2019} & Obs & 117 & 13 & 7 & \\
\hline & Exp & 111.3 & 24.3 & 1.3 & $* * *$ \\
\hline \multirow[t]{2}{*}{09 Sep 2019} & Obs & 137 & 14 & 12 & \\
\hline & Exp & 127.2 & 33.6 & 2.2 & $* * *$ \\
\hline \multirow[t]{2}{*}{19 Sep 2019} & Obs & 121 & 42 & 8 & \\
\hline & Exp & 117.9 & 48.2 & 4.9 & n.s. \\
\hline \multirow[t]{2}{*}{25 Sep 2019} & Obs & 84 & 48 & 9 & \\
\hline & Exp & 82.7 & 50.6 & 7.7 & n.s. \\
\hline
\end{tabular}

It should also be noted that the frequency of the resistance allele $(q)$ experienced a gradual increase over time, from an average of $0.04 \pm 0.01$ in Oct 2018 to $0.25 \pm 0.04$ in Sep 2019 (from data in Figure 2).

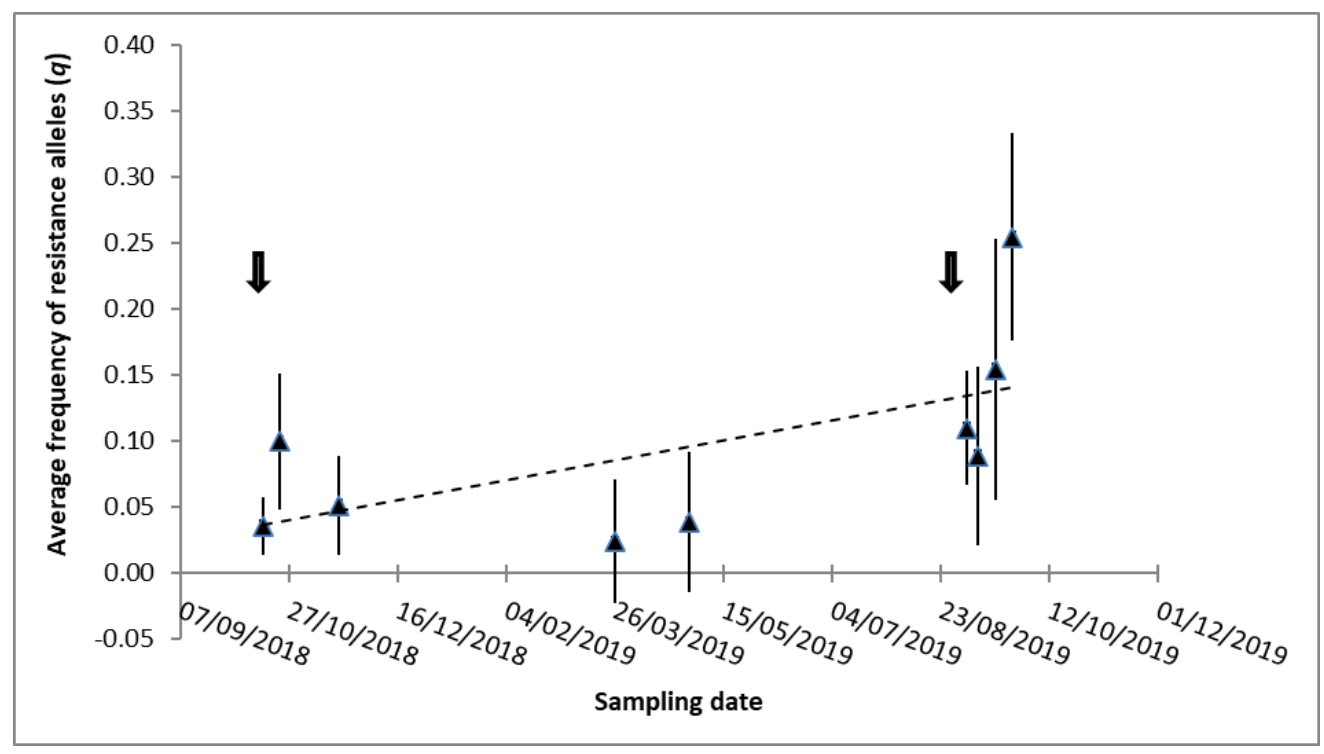


Figure 2. Observed frequency of the resistance allele $(q)$ over time (average across colonies). The error bars indicate the $95 \%$ confidence intervals, and the black arrows indicate the dates of the amitraz treatment.

\section{Discussion}

A widespread and persistent tau-fluvalinate contamination of beeswax and beebread was detected in the hives matrix studied despite that these were not treated with pyrethroids in the previous 48 months. The highest concentrations were found in beebread, probably due to the active migration by diffusion/partition from the beeswax to the stored pollen [40]. Beeswax is a lipophilic matrix that can retain non-polar pesticides, which can therefore be transferred and distributed to other hive products [7, 41, 42]. Thus, higher affinity for lipophilic miticides of beebread compared to wax underlies the concentration of tau-fluvalinate in this matrix [40]. However, these higher concentrations may also be due to the presence of these residues in the pollen collected by bees from crop plants treated with tau-fluvalinate, although the limited use of this active ingredient on crops in the study area (according to official data [43]) does not support this hypothesis. Moreover, the decrease in the average concentration of tau-fluvalinate detected in the beebread collected in spring as opposed to autumn probably reflects a buffering effect due to the input of fresh uncontaminated pollen in spring [44] when foraging activity is at its peak.

The average levels of tau-fluvalinate detected in beebread samples are lower than the LC50 values reported for honey bee larvae (27.69 ppm: [45]) and the concentrations considered to cause high mortality in 1 day-old larvae (3 ppm: [46]). Nevertheless, the presence of tau-fluvalinate residues in all beebread and wax samples is of concern, since the persistence of this pyrethroid in a honey bee colony may have a potentially negative effect on the weight, oviposition and survival of queens, as well as on the sexual competitiveness and survival of drones [47-49]. Given the persistent contamination of beeswax and beebread detected in the hives studied, the honeybees would have been chronically exposed to tau-fluvalinate and thus, toxicological studies evaluating the effect of chronic exposure to this compound are urgently needed.

Another detrimental effect of the continued exposure of honeybee colonies to this chemical may be the selection for resistance in the Varroa mite populations and thus, the loss of tau-fluvalinate efficacy to control varroosis. Indeed, Varroa mites are likely to be exposed to residual tau-fluvalinate directly from the wax, but also from the fat body of honey bees contaminated with these residues (lipophilic pesticides like tau-fluvalinate have been proven to accumulate in the fat body of bees [40,53] and Varroa mites feed primarily on this tissue [4]).

Our results showed an overall excess of resistant genotypes (RR) coupled with an increase of the resistant allele's frequency over time. Given that resistance mutations have been associated with a high fitness cost for Varroa mites and are expected to segregate at increasingly lower frequencies in mite populations in the absence of pyrethroids [50] [21], our results suggest that Varroa chronic exposure to residues of tau-fluvalinate reduced the fitness of sensitive mites (SS and SR), thus exerting a selective pressure for the resistance alleles (R).

The life cycle of the parasite might also influence the frequency of the VGSC genotypes. Varroa mites are known to undergo frequent full sibling mating in the host brood cells under conditions of low mite density and large brood availability (spring and early summer), whereas higher mite density (autumn and winter) prompts outcrossing and recombination [1,52]. Indeed, this inbreeding could partially account for the observed dearth of heterozygotes in most samples relative to HWE expectations, but it does not explain why the concomitant surplus of homozygotes was only observed for pyrethroid resistant individuals (RR) and not for sensitive ones (SS), when the latter are known to have greater fitness than the former [50]. 
At any rate, seasonal fluctuations in the breeding conditions of the mite population may have practical implications. For instance, it has been proposed that in order to minimize selection for the resistant RR genotypes, tau-fluvalinate treatments should be administered when the largest proportion of resistance alleles are in heterozygous mites (i.e. conditions of maximum inbreeding: spring - early summer), while this treatment should be avoided in the strong inbreeding period [52]. However, as deducted from the results in this study, the constant presence of tau-fluvalinate residues in the hive could have counter-effects and render this strategy ineffective.

\section{Conclusions}

Our data revealed the chronic presence of tau-fluvalinate residues in wax and beebread from honey bee colonies that were not treated with pyrethroid acaricides in the previous four years. This was coupled with evidence for selection for pyrethroid-resistant Varroa mites. These results encourage the use of clean, pesticide-free beeswax and the need to regulate the sources of wax being rendered for resale, thereby mitigating the undesired selective effect that these residues may exert on mite populations.

Author Contributions: Conceptualization, M.H.; Methodology and formal analysis and investigation, M.B.-M., MH., R.M.-H., C.Ba., X.M., J.B., J.L.B., M.J.N.; Data collection and curation: M.B.-M, M.H., J.L. B., J.B.; Writing-original draft preparation, M.H., C.Ba., C.Bo., M.B.-M, R.M.-H., J.L.B.; writing-review and editing, M.H., C.Ba., X.M., C.Bo., M.B.-M, J.L.B., A.M., R.M.-H.; project coordination, M.H..; funding acquisition, M.H.

All authors have read and agreed to the published version of the manuscript.

Funding: This research was funded by The National Institute for Agricultural and Food Research and Technology (INIA) and FEDER funds (RTA2017-00004-C02-01) and Instituto Regional de Investigación y Desarrollo Agroalimentario y Forestal (IRIAF).

Acknowledgments: The authors wish to thank V. Albendea, T. Corrales, M. Gajero, C. Uceta, J. Almagro and J. García of the Honey Bee Pathology Laboratory for their technical support.

Conflicts of Interest: The authors declare no conflict of interest.

\section{References}

1. Rosenkranz, P.; Aumeier, P.; Ziegelmann, B. Biology and Control of Varroa destructor. J. Invertebr. Pathol., 2010,103 (SUPPL. 1), S96-S119. https://doi.org/10.1016/j.jip.2009.07.016.

2. Evans, J. D.; Cook, S. C. Genetics and Physiology of Varroa mites. Curr. Opin. Insect Sci., 2018, 26, 130-135. https://doi.org/10.1016/j.cois.2018.02.005.

3. Martin, S. J.; Brettell, L. E. Deformed Wing Virus in honey bees and Other Insects. Annu. Rev. Virol., 2019,6 (June), $49-69$. https://doi.org/10.1146/annurev-virology-092818-015700.

4. Ramsey, S. D.; Ochoa, R.; Bauchan, G.; Gulbronson, C.; Mowery, J. D.; Cohen, A.; Lim, D.; Joklik, J.; Cicero, J. M.; Ellis, J. D.; et al. Varroa destructor Feeds Primarily on Honey Bee Fat Body Tissue and Not Hemolymph. 2018. https://doi.org/10.1073/pnas.1818371116.

5. Annoscia, D.; Brown, S. P.; Di Prisco, G.; De Paoli, E.; Del Fabbro, S.; Frizzera, D.; Zanni, V.; Galbraith, D. A.; Caprio, E.; Grozinger, C. M.; et al. Haemolymph Removal by Varroa Mite Destabilizes the Dynamical Interaction between Immune Effectors and Virus in Bees, as Predicted by Volterra's Model. Proc. R. Soc. B Biol. Sci., 2019, 286 (1901). https://doi.org/10.1098/rspb.2019.0331. 
6. Buendía, M.; Martín-Hernández, R.; Ornosa, C.; Barrios, L.; Bartolomé, C.; Higes, M. Epidemiological Study of Honey bee Pathogens in Europe: The Results of Castilla-La Mancha (Spain). Spanish J. Agric. Res., 2018,16 (2), 1-10. https://doi.org/10.5424/sjar/2018162-11474.

7. Tremolada, P.; Bernardinelli, I.; Colombo, M.; Spreafico, M.; Vighi, M. Coumaphos Distribution in the Hive Ecosystem: Case Study for Modeling Applications. Ecotoxicology, 2004, 13 (6), 589-601. https://doi.org/10.1023/B:ECTX.0000037193.28684.05.

8. Sammataro, D.; De Guzman, L.; George, S.; Ochoa, R.; Otis, G. Standard Methods for Tracheal Mite Research. J. Apic. Res., 2013, 52 (4). https://doi.org/10.3896/IBRA.1.52.4.20.

9. Dmitryjuk, M.; Żółtowska, K.; Frączek, R.; Lipiński, Z. Esterases of Varroa destructor (Acari: Varroidae), Parasitic Mite of the Honey bee. Exp. Appl. Acarol., 2014, 62 (4), 499-510. https://doi.org/10.1007/s10493-013-9754-y.

10. González-Cabrera, J.; Rodríguez-Vargas, S.; Davies, T. G. E.; Field, L. M.; Schmehl, D.; Ellis, J. D.; Krieger, K.; Williamson, M. S. Novel Mutations in the Voltage-Gated Sodium Channel of Pyrethroid-Resistant Varroa destructor Populations from the Southeastern USA. PLoS One, 2016, 11 (5). https://doi.org/10.1371/journal.pone.0155332.

11. Kamler, M.; Nesvorna, M.; Stara, J.; Erban, T.; Hubert, J. Comparison of Tau-Fluvalinate, Acrinathrin, and Amitraz Effects on Susceptible and Resistant Populations of Varroa destructor in a Vial Test. Exp. Appl. Acarol., 2016, 69 (1). https://doi.org/10.1007/s10493-016-0023-8.

12. Higes, M.; Martín-Hernández, R.; Hernández-Rodríguez, C. S.; González-Cabrera, J. Assessing the Resistance to Acaricides in Varroa destructor from Several Spanish Locations. Parasitol. Res., 2020, 119 (11), 3595-3601. https://doi.org/10.1007/s00436-02006879-x.

13. Rinkevich, F. D. Detection of Amitraz Resistance and Reduced Treatment Efficacy in the Varroa Mite, Destructor, within Commercial Beekeeping Operations. PLoS One, 2020, 15 (1), 1-12. https://doi.org/10.1371/journal.pone.0227264.

14. Trouiller, J. Monitoring Varroa jacobsoni Resistance to Pyrethroids in Western Europe. Apidologie, 1998,29 (6), 537-546. https://doi.org/10.1051/apido:19980606.

15. Milani, N. The Resistance of Varroa jacobsoni Oud to Pyrethroids: A Laboratory Assay. Apidologie, 1995,26 (5), $415-429$. https://doi.org/10.1051/apido:19950507.

16. Martin, S. J. Acaricide (Pyrethroid) Resistance in Varroa destructor. Bee World, 2004,85 (4), 67-69. https://doi.org/10.1080/0005772X.2004.11099632.

17. Dong, K.; Du, Y.; Rinkevich, F.; Nomura, Y.; Xu, P.; Wang, L.; Silver, K.; Zhorov, B. S. Molecular Biology of Insect Sodium Channels and Pyrethroid Resistance. Insect Biochem. Mol. Biol., 2014, 50 (1), 1-17. https://doi.org/10.1016/j.ibmb.2014.03.012.

18. Wang, R.; Huang, Z. Y.; Dong, K. Molecular Characterization of an Arachnid Sodium Channel Gene from the Varroa Mite (Varroa destructor). Insect Biochem. Mol. Biol., 2003, 33 (7), 733-739. https://doi.org/10.1016/S0965-1748(03)00068-7.

19. O'Reilly, A. O.; Khambay, B. P. S.; Williamson, M. S.; Field, L. M.; Wallace, B. A.; Davies, T. G. E. Modelling Insecticide-Binding Sites in the Voltage-Gated Sodium Channel. Biochem. J., 2006, 396 (2), 255-263. https://doi.org/10.1042/BJ20051925.

20. González-Cabrera, J.; Davies, T. G. E.; Field, L. M.; Kennedy, P. J.; Williamson, M. S. An Amino Acid Substitution (L925V) Associated with Resistance to Pyrethroids in Varroa destructor. PLoS One, 2013, 8 (12). https://doi.org/10.1371/journal.pone.0082941.

21. González-Cabrera, J.; Bumann, H.; Rodríguez-Vargas, S.; Kennedy, P. J.; Krieger, K.; Altreuther, G.; Hertel, A.; Hertlein, G.; Nauen, R.; Williamson, M. S. A Single Mutation Is Driving Resistance to Pyrethroids in European Populations of the Parasitic Mite, Varroa destructor. J. Pest Sci. (2004)., 2018, 91 (3), 1137-1144. https://doi.org/10.1007/s10340-018-0968-y.

22. Alissandrakis, E.; Ilias, A.; Tsagkarakou, Pyrethroid resistance in Greek populations of the honey bee parsite Varroa destructor (Acari: Varroidae). J. Apic. Res., 2017, 56 (5), 625-630. https://doi.org/10.1080/00218839.2017.1368822.

23. Panini, M.; Reguzzi, M. C.; Chiesa, O.; Cominelli, F.; Lupi, D.; Moores, G.; Mazzoni, E. Pyrethroid Resistance in Italian Populations of the Mite Varroa destructor: A Focus on the Lombardy Region. Bull. Insectology, 2019, 72 (2), $227-232$.

24. Reeves, A. M.; O’Neal, S. T.; Fell, R. D.; Brewster, C. C.; Anderson, T. D. In-Hive Acaricides Alter Biochemical and Morphological Indicators of Honey Bee Nutrition, Immunity, and Development. J. Insect Sci., 2018, 18 (5). https://doi.org/10.1093/jisesa/iey086.

25. Ogihara, S.; Inoue, O.; Yamagami, T.; Yanagimoto, K.; Uematsu, K.; Hisada, Y.; Uchida, T.; Ohta, M.; Suzuki-Inoue, K. Clinical Characteristics and Molecular Analysis of USA300 and ST 764 Methicillin-Resistant Staphylococcus Aureus Isolates from Outpatients in Japan by PCR-Based Open Reading Frame Typing. J. Infect. Chemother., 2021,27 (3), $466-472$. https://doi.org/10.1016/j.jiac.2020.10.023.

26. Chauzat, M.-P.; Faucon, J.-P.; Martel, A.-C.; Lachaize, J.; Cougoule, N.; Aubert, M. A Survey of Pesticide Residues in Pollen Loads Collected by Honey Bees in France. J. Econ. Entomol., 2009, 99 (2), 253-262. https://doi.org/10.1603/0022-0493-99.2.253.

27. Mullin, C. A.; Frazier, M.; Frazier, J. L.; Ashcraft, S.; Simonds, R.; vanEngelsdorp, D.; Pettis, J. S. High Levels of Miticides and Agrochemicals in North American Apiaries: Implications for Honey Bee Health. PLoS One, 2010,5 (3). https://doi.org/10.1371/journal.pone.0009754.

28. Orantes-Bermejo, F. J.; Pajuelo, A. G.; Megías, M. M.; Fernández-Píñar, C. T. Pesticide Residues in Beeswax and Beebread Samples Collected from Honey Bee Colonies (Apis Mellifera L.) in Spain. Possible Implications for Bee Losses. J. Apic. Res., 2010, 49 (3), 243-250. https://doi.org/10.3896/IBRA.1.49.3.03.

29. Simon-Delso, N.; Martin, G. S.; Bruneau, E.; Minsart, L. A.; Mouret, C.; Hautier, L. Honey bee Colony Disorder in Crop Areas: The Role of Pesticides and Viruses. PLoS One, 2014, 9 (7), 1-16. https://doi.org/10.1371/journal.pone.0103073. 
30. Wilmart, O.; Legrève, A.; Scippo, M. L.; Reybroeck, W.; Urbain, B.; De Graaf, D. C.; Steurbaut, W.; Delahaut, P.; Gustin, P.; Nguyen, B. K.; et al. Residues in Beeswax: A Health Risk for the Consumer of Honey and Beeswax? J. Agric. Food Chem., 2016, 64 (44), 8425-8434. https://doi.org/10.1021/acs.jafc.6b02813.

31. Calatayud-Vernich, P.; Calatayud, F.; Simó, E.; Picó, Y. Pesticide Residues in Honey Bees, Pollen and Beeswax: Assessing Beehive Exposure. Environ. Pollut., 2018, 241, 106-114. https://doi.org/10.1016/j.envpol.2018.05.062.

32. Manning, R. Chemical Residues in Beebread, Honey, Pollen and Wax Samples Collected from Bee Hives Placed on Canola Crops in Western Australia. J. Apic. Res., 2018, 57 (5), 696-708. https://doi.org/10.1080/00218839.2018.1494889.

33. Alonso-Prados, E.; Muñoz, I.; De la Rúa, P.; Serrano, J.; Fernández-Alba, A. R.; García-Valcárcel, A. I.; Hernando, M. D.; Alonso, Á.; Alonso-Prados, J. L.; Bartolomé, C.; et al. The Toxic Unit Approach as a Risk Indicator in Honey Bees Surveillance Programmes: A Case of Study in Apis Mellifera Iberiensis. Sci. Total Environ., 2020, 698, 134208. https://doi.org/10.1016/j.scitotenv.2019.134208.

34. Li, Y.; Kelley, R. A.; Anderson, T. D.; Lydy, M. J. Development and Comparison of Two Multi-Residue Methods for the Analysis of Select Pesticides in Honey Bees, Pollen, and Wax by Gas Chromatography-Quadrupole Mass Spectrometry. Talanta, 2015, 140, 81-87. https://doi.org/10.1016/j.talanta.2015.03.031.

35. Svečnjak, L.; Chesson, L. A.; Gallina, A.; Maia, M.; Martinello, M.; Mutinelli, F.; Muz, M. N.; Nunes, F. M.; Saucy, F.; Tipple, B. J.; et al. Standard Methods for Apis Mellifera Beeswax Research. J. Apic. Res., 2019,58 (2), 1-108. https://doi.org/10.1080/00218839.2019.1571556.

36. España, G. de. Disposición Final Quinta. In REAL DECRETO 608/2006, de 19 de mayo, por el que se establece y regula un Programa nacional de lucha y control de las enfermeda- des de las abejas de la miel.; Dykinson, 2006; pp 1097-1102. https://doi.org/10.2307/j.ctv9hvtfd.120.

37. Stara, J.; Pekar, S.; Nesvorna, M.; Kamler, M.; Doskocil, I.; Hubert, J. Spatio-Temporal Dynamics of Varroa destructor Resistance to Tau-Fluvalinate in Czechia, Associated with L925V Sodium Channel Point Mutation. Pest Manag. Sci., 2019, 75 (5), $1287-$ 1294. https://doi.org/10.1002/ps.5242.

38. Martín-Hernández, R.; Botías, C.; Bailón, E. G.; Martínez-Salvador, A.; Prieto, L.; Meana, A.; Higes, M. Microsporidia Infecting Apis Mellifera: Coexistence or Competition. Is Nosema Ceranae Replacing Nosema Apis? Environ. Microbiol., 2012, 14 (8), 2127-2138. https://doi.org/10.1111/j.1462-2920.2011.02645.x.

39. Millán-Leiva, A.; Hernández-Rodríguez, C. S.; González-Cabrera, J. New PCR-RFLP Diagnostics Methodology for Detecting Varroa destructor Resistant to Synthetic Pyrethroids. J. Pest Sci. (2004)., 2018, 91 (3), 937-941. https://doi.org/10.1007/s10340-0180964-2.

40. Fulton, C. A.; Huff Hartz, K. E.; Fell, R. D.; Brewster, C. C.; Reeve, J. D.; Lydy, M. J. An Assessment of Pesticide Exposures and Land Use of Honey Bees in Virginia. Chemosphere, 2019, 222, 489-493. https://doi.org/10.1016/j.chemosphere.2019.01.156.

41. Kochansky, J.; Wilzer, K.; Feldlaufer, M. Comparison of the Transfer of Coumaphos from Beeswax into Syrup and Honey. Apidologie, 2001, 32 (2), 119-125. https://doi.org/10.1051/apido:2001117.

42. Wu, J. Y.; Anelli, C. M.; Sheppard, W. S. Sub-Lethal Effects of Pesticide Residues in Brood Comb on Worker Honey Bee (Apis Mellifera) Development and Longevity. PLoS One, 2011, 6 (2). https://doi.org/10.1371/journal.pone.0014720.

43. Ministerio de Agricultura, P. y A. Encuesta de Utilización de Productos Fitosanitarios 2013. 2016.

44. Sponsler, D. B.; Johnson, R. M. Mechanistic Modeling of Pesticide Exposure: The Missing Keystone of Honey Bee Toxicology. Environ. Toxicol. Chem., 2017, 36 (4), 871-881. https://doi.org/10.1002/etc.3661.

45. Dai, P.; Jack, C. J.; Mortensen, A. N.; Ellis, J. D. Acute Toxicity of Five Pesticides to Apis Mellifera Larvae Reared in Vitro. Pest Manag. Sci., 2017, 73 (11), 2282-2286. https://doi.org/10.1002/ps.4608.

46. Zhu, W.; Schmehl, D. R.; Mullin, C. A.; Frazier, J. L. Four Common Pesticides, Their Mixtures and a Formulation Solvent in the Hive Environment Have High Oral Toxicity to Honey Bee Larvae. PLoS One, 2014, 9 (1). https://doi.org/10.1371/journal.pone.0077547.

47. Sokól, R. Wpływ Wielomiesięcznego Pozostawania. 1996, 52 (Ii), 718-720.

48. Rinderer, T. E.; De Guzman, L. I.; Lancaster, V. A.; Delatte, G. T.; Stelzer, J. A. Varroa in the Mating Yard: I. The Effects of Varroa jacobsoni and Apistan ${ }^{\circledR}$ on Drone Honey Bees. Am. Bee J., 1999, 139 (2), 134-139.

49. Haarmann, T.; Spivak, M.; Weaver, D.; Weaver, B.; Glenn, T. Effects of Fluvalinate and Coumaphos on Queen Honey Bees (Hymenoptera: Apidae) in Two Commercial Queen Rearing Operations. J. Econ. Entomol., 2002,95 (1), $28-35$. https://doi.org/10.1603/0022-0493-95.1.28.

50. Kliot, A.; Ghanim, M. Fitness Costs Associated with Insecticide Resistance. Pest Manag. Sci., 2012,68 (11), $1431-1437$. https://doi.org/10.1002/ps.3395.

51. Blenau, W.; Rademacher, E.; Baumann, A. Plant Essential Oils and Formamidines as Insecticides/ Acaricides: What Are the Molecular Targets? Apidologie, 2012, 43 (3), 334-347. https://doi.org/10.1007/s13592-011-0108-7.

52. Beaurepaire, A. L.; Krieger, K. J.; Moritz, R. F. A. Seasonal Cycle of Inbreeding and Recombination of the Parasitic Mite Varroa destructor in Honey bee Colonies and Its Implications for the Selection of Acaricide Resistance. Infect. Genet. Evol., 2017, 50 (February), 49-54. https://doi.org/10.1016/j.meegid.2017.02.011.

53. Tadei, R.; Domingues, C. E. C.; Malaquias, J. B.; Camilo, E. V.; Malaspina, O.; Silva-Zacarin, E. C. M. Late Effect of Larval CoExposure to the Insecticide Clothianidin and Fungicide Pyraclostrobin in Africanized Apis Mellifera. Sci. Rep., 2019,9 (1), 1-11. https://doi.org/10.1038/s41598-019-39383-z. 